Pacific Journal of Mathematic 


\title{
ON THE COMPLEX ZEROS OF FUNCTIONS OF STURM-LIOUVILLE TYPE
}

\author{
CHOY-TAK TAAM
}

1. Let $Q(z)$ be an analytic function of the complex variable $z$ in a region $D$. In the present paper only those solutions of

$$
W^{\prime \prime}+Q(z) W=0
$$

which are distinct from the trivial solution $(\equiv 0)$ shall be considered.

In this paper the following results shall be established.

THEOREM 1. Suppose that the following conditions are satisfied:

(a) the circle $|z| \leq R$ is contained in $D$,

(b) $W(z)$ is a solution of $(1.1), W(0) \neq 0$,

(c) $n(r)$ is the number of zeros of $\mathbb{W}(z)$ in $|z| \leq r, r<R$.

Then $n(r)$ satisfies the inequality

$$
\begin{aligned}
n(r) \leq & \left(\log \left(R r^{-1}\right)\right)^{-1}\left[\log \left(1+R\left|\mathbb{W}^{\prime}(0)\right||W(0)|^{-1}\right)\right. \\
& \left.+(2 \pi)^{-1} \int_{0}^{2 \pi} \int_{0}^{R}(R-t)\left|Q\left(t e^{i \theta}\right)\right| d t d \theta\right] .
\end{aligned}
$$

COROLLARY 1.1. Suppose that the following conditions are satisfied:

(a) $Q(z)$ is a polynomial of degree $k$,

(b) conditions ( $\mathrm{b}$ ) and ( c) of Theorem 1 hold.

Then $W(z)$ is an integral function of order at most $k+2$. Furthermore, as $r \longrightarrow \infty$,

$$
n(r)=O\left(r^{k+2}\right) \text {. }
$$

Obviously the result of Theorem 1 is not good if $r$ is close to $R$. Also it

\footnotetext{
Received August 30, 1952.
}

Pacific J. Math. 3 (1953), $837-843$ 
does not apply to a solution which vanishes at the origin. The following theorem is free of these restrictions.

THEOREM 2. Suppose that the following conditions are satisfied:

(a) $S$ is a closed region contained in $D_{\text {, }}$

(b) the boundary $C$ of $S$ is a closed contour,

(c) the maximum value of $|Q(z)|$ on $C$ is $M$,

(d) $S$ can be aivided into $n$ subregions such that each subregion has a diameter not greater than $\pi \mathrm{M}^{-1 / 2}$; and for any two points $z_{1}$ and $z_{2}$ of a subregion, the linear segment $z_{1} z_{2}$ lies in $S$ (we agree that the common boundary of two subregions belongs to both subregions).

Then

(e) if $Q(z)$ is not a constant, the number of zeros of any solution $\mathbb{W}(z)$ of (1.1) in $S$ is not greater than $n$,

(f) more accurately, if $Q(z)$ is not a constant, each solution $\mathbb{W}(z)$ of (1.1) has at most one zero in each subregion, and when it is known that $\mathbb{W}(z)$ has some zero $z_{i}$ which belongs to $n_{i}\left(n_{i}>1\right)$ different subregions, $i=1,2$, $\cdots, k$, its total number of zeros in $S$ is not greater than $n+k-\left(n_{1}+n_{2}+\cdots+\right.$ $\left.n_{k}\right)$,

(g) if some solution of (1.1) has more than one zero in some subregion, $Q(z)$ must be a constant and $|Q(z)|=M>0$ in $L$.

We may observe that if $Q(z)$ is not a constant, $M$ must be positive, according to the principle of the maximum modulus. If $Q(z)$ is a constant, the problem is trivial as the distribution of the zeros is known.

2. To prove Theorem 1, we need the following known results.

LEMMA 1. Suppose that the following conditions are satisfied:

(a) $f(x)$ and $g(x)$ are real-valued functions, continuous and nonnegative for $x \geq 0$,

(b) $M$ is a positive constant,

(c) $f(x) \leq M+\int_{0}^{x} f(t) g(t) d t$, $x \geq 0$ 


$$
f(x) \leq M e^{\int_{0}^{x} g(t) d t}
$$$$
x \geq 0 \text {. }
$$

This lemma is due to R. Bellman. For a proof of it see [1] or [5].

Lemma 2. Suppose that the following conditions are satisfied:

(a) $f(z)$ is analytic for $|z| \leq R, f(0) \neq 0$,

(b) the moduli of the zeros of $f(z)$ in the circle $|z| \leq R$ are $r_{1}, r_{2}, \cdots, r_{k}$ arranged as a nondecreasing sequence (a zero of order $p$ is counted $p$ times).

Then we have

$$
\log \left[R^{k}\left(r_{1} r_{2} \cdots r_{k}\right)^{-1}\right]=(2 \pi)^{-1} \int_{0}^{2 \pi} \log \left|f\left(R e^{i \theta}\right)\right| d \theta-\log |f(0)| .
$$

Lemma 2 is known as Jensen's theorem (see [4]).

3. Now we shall prove Theorem 1. Along a fixed ray radiating out from the origin, $z=r \exp (i \theta)$, equation (1.1) becomes

$$
\frac{d^{2} \mathbb{W}}{d r^{2}}+e^{2 i \theta} Q\left(r e^{i \theta}\right) \mathbb{W}=0
$$

Integrating (3.1) twice from 0 to $r$, we obtain

$$
\mathbb{W}\left(r e^{i \theta}\right)=\mathbb{W}(0)+\mathbb{W}^{\prime}(0) e^{i \theta} r-e^{2 i \theta} \int_{0}^{r} \int_{0}^{h} Q\left(t e^{i \theta}\right) \mathbb{W}\left(t e^{i \theta}\right) d t d h,
$$

where $W^{\prime}(0) \exp (i \theta)$ is the value of $d W / d r$ at the origin. Integration by parts of the integral in (3.2) gives

$$
W\left(r e^{i \theta}\right)=W(0)+W^{\prime}(0) e^{i \theta} r-e^{2 i \theta} \int_{0}^{r}(r-t) Q\left(t e^{i \theta}\right) W\left(t e^{i \theta}\right) d t
$$

For $r \leq R,(3.3)$ yields

$$
\left|W\left(r e^{i \theta}\right)\right| \leq|W(0)|+\left|W^{\prime}(0)\right| R+\int_{0}^{r}(R-t)\left|Q\left(t e^{i \theta}\right) W\left(t e^{i \theta}\right)\right| d t .
$$

Applying Lemma 1 to (3.4), we have

$$
\left|\mathbb{W}\left(R e^{i \theta}\right)\right| \leq\left(|W(0)|+\left|W^{\prime}(0)\right| R\right) e^{\int_{0}^{R}(R-t)\left|Q\left(t e^{i \theta}\right)\right| d t} .
$$


Let the moduli of the zeros of $\mathbb{W}(z)$ in the circle $|z| \leq r<R$ be $r_{1}, r_{2}, \ldots, r_{k}$, arranged as a nondecreasing sequence. Then an appeal to Lemma 2 gives

(3.6) $\log \left[R^{k}\left(r_{1} r_{2} \cdots r_{k}\right)^{-1}\right] \leq(2 \pi)^{-1} \int_{0}^{2 \pi} \log \left|W\left(R e^{i \theta}\right)\right| d \theta-\log |W(0)|$. Clearly

$$
\begin{array}{rlrl}
\log \left[R^{k}\left(r_{1} r_{2} \cdots r_{k}\right)^{-1}\right] & \geq \log \left[R^{n(r)} r^{-n(r)}\right] \\
& =n(r) \log \left(R r^{-1}\right), & r<R,
\end{array}
$$

where $n(r)$ is the number of zeros of $W(z)$ in $|z| \leq r$. On the other hand, $(3.5)$ gives

$$
\begin{aligned}
\int_{0}^{2 \pi} \log \left|W\left(R e^{i \theta}\right)\right| d \theta & \leq 2 \pi \log \left[|\mathbb{W}(0)|+\left|W^{\prime}(0)\right| R\right] \\
& +\int_{0}^{2 \pi} \int_{0}^{R}(R-t)\left|Q\left(t e^{i \theta}\right)\right| d t d \theta .
\end{aligned}
$$

Combining (3.6), (3.7), and (3.8), we have

$$
\begin{aligned}
n(r) \log \left(R r^{-1}\right) \leq & \log \left[|\mathbb{W}(0)|+\left|W^{\prime}(0)\right| R\right]-\log |\mathbb{W}(0)| \\
& +(2 \pi)^{-1} \int_{0}^{2 \pi} \int_{0}^{R}(R-t)\left|Q\left(t e^{i \theta}\right)\right| d t d \theta
\end{aligned}
$$

for $r<R$. But (3.9) is equivalent to (1.2), so that this completes the proof of Theorem 1 .

If $Q(z)$ is a polynomial of degree $k$, then $W(z)$ is analytic except at infinity and, from (3.5),

$$
\left|W\left(R e^{i \theta}\right)\right|=O\left(e^{A \cdot R^{k+2}}\right),
$$

where $A$ is a constant. Hence $\mathbb{W}(z)$ is an integral function of order at most $k+2$. Finally if we set $R=2 r$ in (3.9), it is clear that

$$
n(r)=O\left(r^{k+2}\right) \text {. }
$$

This proves Corollary 1.1. 
4. To prove Theorem 2, we need the following known result. On the real axis, equation (1.1) becomes

$$
\frac{d^{2} W}{d x^{2}}+Q(x) W=0
$$

where $x$ is the real part of the complex variable $z$. Denote by $q_{1}(x)$ the real part of $Q(x)$.

LEMMA 3. Let $W(x)$ be a solution of $(4.1), W(0)=0$. Suppose that one of the following conditions is satisfied.

(a) $\max q_{1}(x)=m>0$ in $[0, a], 0<a \leq \pi m^{-1 / 2}$, and $Q(x) \not \equiv m$ in $[0, a]$,

(b) $q_{1}(x) \leq 0$ in $[0, a]$.

Then $W(x) \neq 0$ in $(0, a]$.

This lemma was proved in [3; Theorems 5.1, 5.2]. Part (b) is also covered by a theorem of Ilille [2, p. $512 \mathrm{ff}$.]. Its proof remains valid even if $Q(x)$ is assumed only to be a continuous (complex-valued) function of a real variable $x$; consequently the lemma remains true under such an assumption on $Q(x)$.

We first prove $(f)$ of Theorem 2.

Let $S_{i}$ be one of the subregions of $S$ with a diameter not greater than $\pi M^{-1 / 2}$. Suppose that $\mathbb{W}(z)$ is a solution of (1.1) which vanishes at a point $z_{0}$, say, of $S_{i}$. Consider a fixed ray radiating out from $z_{0}, z-z_{0}=r \exp (i \theta)$. Along this ray, equation (1.1) becomes

$$
\frac{d^{2} W}{d r^{2}}+e^{2 i \theta} Q\left(z_{0}+r e^{i \theta}\right) W=0
$$

By virtue of the principle of the maximum modulus, we have

$$
\left|e^{2 i \theta} Q(z)\right|=|Q(z)| \leq M
$$

for any point $z$ of $S$ on this ray. Hence on a segment of this ray between $z_{0}$ and any other point of $S_{i}$ (by assumption, this segment lies in $S$ ) the maximum value $m$, say, of the real part of $\exp (2 i \theta) Q(z)$ is not greater than $M$. If $m$ is positive, then $\pi m^{-1 / 2} \geq \pi M^{-1 / 2}$. Since $Q(z)$ is not a constant, $\exp (2 i \theta) Q(z) \not \equiv$ $m$ on this segment. By virtue of the fact that the diameter of $S_{i}$ is not greater 
than $\pi M^{-1 / 2}$ and Lemma 3, it is clear that $W(z)$ does not vanish again on that part of the ray in $S_{i}$, regardless of the sign of $m$. Repeating this process for each ray radiating out from $z_{0}$, we see clearly that $\mathbb{W}(z)$ cannot vanish again in $S_{i}$. Since $S_{i}$ is an arbitrary subregion, $\mathbb{W}(z)$ can vanish at most at one point of each subregion.

On the other hand, if $W(z)$ has a zero $z_{i}$ which belongs to $n_{i}\left(n_{i}>1\right)$ different subregions, then $W(z)$ cannot vanish again in any of these $n_{i}$ subregions, as the foregoing proof shows. If it is known that there are $k$ such zeros $z_{i}$, each $z_{i}$ belonging to $n_{i}$ subregions, $i=1,2, \ldots, k$, it is clear that the total number of zeros of $\mathbb{W}(z)$ in $S$ is not greater than $n+k-\left(n_{1}+n_{2}+\cdots\right.$ $\left.+n_{k}\right)$.

To prove $(g)$, let $W(z)$ be a solution of (1.1) having two zeros, say $z_{0}$ and $z_{1}$, in some subregion $S_{i}$. Let the argument of $z_{1}-z_{0}$ be $\theta$. Then along the linear segment $z_{0} z_{1}$, equation (1.1) becomes (4.2). According to Lemma 3, the maximum value $m$ of the real part of $\exp (2 i \theta) Q(z)$ on the linear segment $z_{0} z_{1}$ must be positive. Further, since

$$
\left|z_{1}-z_{0}\right| \leq \pi M^{-1 / 2} \leq \pi m^{-1 / 2},
$$

$z_{0}$ and $z_{1}$ can both be the zeros of $\mathbb{W}(z)$ only if

$$
e^{2 i \theta} Q(z) \equiv m
$$

on the linear segment $z_{0} z_{1}$, by Lemma 3 again. But if (4.4) is true, the general solution of (4.2) is $A \sin \left(m^{1 / 2} r+B\right), A$ and $B$ being constants. If a solution of (4.2) has two zeros, the distance between them must not be less than $\pi m^{-1 / 2}$. In other words, the equality signs in (4.3) must hold. That is, $M=m$. From (4.4), we have $\exp (2 i \theta) Q(z) \equiv M$ on the linear segment $z_{0} z_{1}$. Since $Q(z)$ is an analytic function and constant on the linear segment $z_{0} z_{1}, Q(z)$ is a constant in $D$. Obviously $|Q(z)|=M$; and since $m$ is positive, so is $M$. This proves $(g)$.

Clearly $(e)$ follows from $(f)$, and this completes the proof of Theorem 2.

5. Added in proof. The author is indebted to a referee for calling his attention to the fact that, in connection with Corollary 1.1 , an entire function which satisfies a linear differential equation with coefficients which are rational functions of $z$ is always of finite rational order and of perfectly regular 
growth. (See G. Valiron, Lectures on the theory of integral functions, Toulouse, 1923, p. 106 ff. )

\section{REFERENCES}

1. R. Bellman, The boundedness of solutions of linear differential equations, Duke Math. J. 14 (1947), $83-97$.

2. E. L. Ince, Ordinary differential equations, London, 1927.

3. C. T. Taam, Oscillation the orems, Amer. J. Math. 74 (1952), 317-324.

4. E. C. Titchmarsh, The theory of functions, Oxford, 1944.

5. H. Weyl, Comment on the preceding paper, Amer. J. Math. 68 (1946), 7-12.

The UNIVERSITy OF Missouri and

The Catholic University of America 
The editors gratefully acknowledge the services of the following persons not members of the Editorial Staff who have been consulted concerning the preparation of the third volume of this Journal:

R.P. Agnew, C.B. Allendoerfer, T.M. Apostol, Richard Arens, Nachman Aronszajn, R. Baer, R.E. Bellman, Stefan Bergman, Garrett Birkhoff, L.M. Blumenthal, R.P. Boas, Jr., H.E. Bray, F.E. Browder, R.C. Buck, C. Chevalley, I.S. Cohen, H.V. Craig, J.L. Doob, R.J. Duffin, Nelson Dunford, W.F. Eberlein, Arthur Erdélyi, H. Federer, Werner Fenchel, N.J. Fine, Harley Flanders, G.E. Forsythe, I.S. Gal, P.R. Garabedian, Wallace Givens, L.M. Graves, J.W. Green, W. Gustin, M. Hall, T.E. Harris, Olaf Helmer, I.N. Herstein, J.D. Hill, E. Hille, P. Hodge, R.C. James, R.D. James, F. John, S. Johnson, Jan Kalicki, Irving Kaplansky, W. Karush, M.S. Knebelman, R.M. Lakness, D. H. Lehmer, N. Levinson, Lee Lorch, M. M. Loève, R. C. Lyndon, G. R. MacLane, J. C. C. McKinsey, N.H. McCoy, Wilhelm Magnus, H.B. Mann, W.R. Mann, E. Michael, C.B. Morrey, Jr., T. Motzkin, Ivan Niven, L.J. Paige, H. Rademacher, R.M. Redheffer, W.T. Reid, J. Riordan, M.S. Robertson, J. Robinson, W.E. Roth, H.S. Ruse, Peter Scherk, W. Seidel, H.N. Shapiro, H. Shniad, D.C. Spencer, N.E. Steenrod, J.J. Stoker, D. Swift, Gabor Szegö, E.W. Titt, A.W. Tucker, F.A. Valentine, H.S. Vandiver, R. Wagner, J.L. Walsh, S.S. Walters, Morgan Ward, H.F. Weinberger, A. Weinstein, A.L. Whiteman, L.R. Wilcox, Frantisek Wolf, J. Wolfowitz, D. Zelinsky, M. Zorn, A. Zygmund. 


\title{
PACIFIC JOURNAL OF MATHEMATICS
}

\author{
EDITORS
}

\author{
R. M. BOEINSON \\ University of California \\ Berkeley 4, California \\ E. HEWITT \\ University of Washington \\ Seattle 5, Washington
}

\author{
P. P. DILWOR TH \\ California Institute of Technology \\ Pasadena 4, California \\ E. F. BECKENBACH \\ University of California \\ Los Angeles 24, California
}

\section{ASSOCIATE EDITORSS}

$\begin{array}{llll}\text { H. BUSEMANN } & \text { P. R. HALMOS } & \text { BØRGE JESSEN } & \text { J. J. STOKER } \\ \text { HERBERT FFDERER } & \text { HEINZ HOPF } & \text { PAUL LÉVY } & \text { E. G. STR AUS } \\ \text { MARSHALL HALI } & \text { R. D. JAMES } & \text { GEORGE PÓLYA } & \text { KÔSAKU YOSIDA }\end{array}$

\section{SFONSORS}

UNIVERSITY OF BRITISH COLUMBIA

CALIFORNIA INSTITUTE OF TECHNOLOGY.

UNIVERSITY OF CAIIFORNIA, BERKELEY

UNIVERSITY OF CALIFORNIA, DAVIS

UNIVERSITY OF CALIFORNIA, LOS ANGELES

UNIVERSITY OF CALIFORNIA, SANTA BARBARA

UNIVERSITY OF NEVADA

OREGON STATE COLLEGE

UNIVERSITY OF OREGON

\author{
UNIVERSITY OF SOU THERN CALIFORNIA \\ STANFORD RESEARCH INSTITUTE \\ STANFORD UNIVERSITY. \\ WASHINGTON STATE COLLEGE \\ UNIVERSITY OF WASHINGTON \\ AMERICAN MATHEMATICAL SOCIETY \\ NATIONAL BUREAU OF STANDARDS, \\ INSTITUTE FOR NUMERICAL ANALYSIS
}

Mathematical papers intended for publication in the Pacific Journal of Mathematics should be typewritten (double spaced), and the author should keep a complete copy. Manuscripts may be sent to any of the editors-except Robinson, whose term expires with the completion of the present volume; they might also be sent to M.M. Schiffer, Stanford University, Stanford, California, who is succeeding Robinson. All other communications to the editors should be addressed to the managing editor, $\mathrm{E}$. F. Beckenbach, at the address given above.

Authors are entitled to receive 100 free reprints of their published papers and may obtain additional copies at cost.

The Pacific Journal of Mathematics is published quarterly, in March, June, September, and December. The price per volume (4 numbers) is $\$ 8.00$; single issues, $\$ 2.50$. Special price to individual faculty members of supporting institutions and to individual members of the American Mathematical Society: $\$ 4.00$ per volume; single issues, $\$ 1.25$.

Subscriptions, orders for back numbers, and changes of address should be sent to the publishers, University of California Press, Berkeley 4, California.

Printed at Ann Arbor, Michigan. Entered as second class matter at the Post Office, Berkeley, California.

\author{
UNIVERSITY OF CALIFORNIA PRESS - BERKELEY AND LOS ANGELES
}




\section{Pacific Journal of Mathematics}

\section{Vol. 3, No. $4 \quad$ June, 1953}

Paul Erdős and Gilbert Agnew Hunt, Jr., Changes of sign of sums of random variables........................................ 673

Paul Erdôs and Ernst Gabor Straus, On linear independence of sequences in

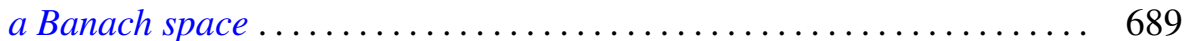

Haim Hanani, On sums of series of complex numbers ............... 695

Melvin Henriksen, On the prime ideals of the ring of entire functions ..... 711

Irving Kaplansky, Completely continuous normal operators with property L............................................. 721

Samuel Karlin, Some random walks arising in learning models. I. ...... 725

William Judson LeVeque, On uniform distribution modulo a subdivision ..................................... 757

Lee Lorch, Derivatives of infinte order ..................... 773

Ernest A. Michael, Some extension theorems for continuous functions . . . . . 789

Tyre Alexander Newton, A note on the Hölder mean ................ 807

Raymond Moos Redheffer, On a theorem of Plancherel and Pólya....... 823

Choy-Tak Taam, On the complex zeros of functions of Sturm-Liouville

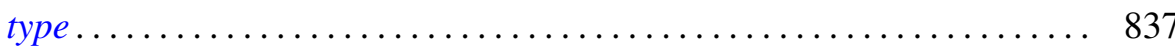

